\title{
The Legislative and Policy Gaps in the National HIV and AIDS, STI Policy, 2004-2014, Ghana
}

\author{
Ishmael D. Norman ${ }^{1,2^{*}}$, Margaret Kweku${ }^{1}$, Gideon Kye-Duodu ${ }^{1}$, Joyce Der ${ }^{1}$, \\ Blandina M. Awiah ${ }^{2}$, Fred N. Binka ${ }^{3}$ \\ ${ }^{1}$ School of Public Health, University of Health and Allied Sciences (Hohoe Campus), Hohoe, Volta Region, Ghana \\ ${ }^{2}$ Institute for Security, Disaster and Emergency Studies, Sandpiper Place, Langma, Central Region, Ghana \\ ${ }^{3}$ University of Health and Allied Sciences, Ho, Volta Region, Ghana \\ Email: ishmael_norman@yahoo.com,margaretkweku069@gmail.com, blandinaawiah@gmail.com, \\ fred.binka@gmail.com
}

Received 7 October 2015; accepted 13 December 2015; published 16 December 2015

Copyright (C) 2015 by authors and Scientific Research Publishing Inc.

This work is licensed under the Creative Commons Attribution International License (CC BY). http://creativecommons.org/licenses/by/4.0/

(c) (i) Open Access

\section{Abstract}

By 2003, 350,000 persons lived with HIV/AIDS in Ghana with an average drop of 15,640 over 8 years. In 2011, approximately 224,878 persons lived with HIV/AIDS, which is expected to drop to 221,884 by 2015 . We think the estimated 2994 drop over 4 years is pedestrian. We attribute the lackluster performance to the haphazard HIV and AIDS, STI Policy from 2004 through 2013. We considered the Ghana HIV/AIDS and STI Policy published (NACP/GHS, 2013) "as is" to isolate the gaps in the policy, looking at the provision of judicial and legal mechanisms for testing, treatment and counseling. We also investigated the national policy on partner notification, names reporting, and expedited partner therapy, in the case of MSM and young people as provided for in the policy. Finally, we looked at issues affecting stigmatization and discrimination. The investigation consisted of the review of the Revised National HIV and AIDS, STI Policy of August 2004 through 2013. We also undertook a documentary review of publications on the topic. There are systemic problems in the policy design, which has weakened the thrust of the national control program. The policy is unsystematic and inconsistent with international best practice in combating communicable diseases. It may not maximize the number of persons who are aware of their HIV status. It may not increase the number of HIV infected persons who receive care, and may not prevent new infections. It is unlikely that by 2015 even the low 2994 drop over four years would be sustained particularly with the current rationing of ART drugs in the nation. Recommendations are made to, perhaps, inform policy.

${ }^{*}$ Corresponding author.

How to cite this paper: Norman, I. D., Kweku, M., Kye-Duodu, G., Der, J., Awiah, B. M., \& Binka, F. N. (2015). The Legislative and Policy Gaps in the National HIV and AIDS, STI Policy, 2004-2014, Ghana. Beijing Law Review, 6, 311-319.

http://dx.doi.org/10.4236/blr.2015.64027 
Keywords

HIV/AIDS, Legislative and Policy Gaps, Partner Notification, Names Reporting, Expedited Partner Therapy, MSM, Ghana

\section{Introduction}

In 2011, approximately 224,878 persons lived with HIV/AIDS in Ghana. An equal number of those identified as living with HIV/AIDS, may be infected and may not have been identified due to lack of testing. At the same time, there were 12,077 new infections in 2011 with anticipated decrease in new infections by 2015 to be 9022 . The estimated deaths from HIV/AIDS in 2011 were 15,263 but it was expected to fall to 6350 by 2012 (National AIDS Control Programme, 2013). By the time of promulgating the new policy under review, estimates for 2012 should have been realized and changed to actual cases. At any rate, the number of children in 2011 with HIV/ AIDS was 1707, which is to fall to 824 in 2015 (National AIDS Control Programme, 2013). Such estimates are dependent on the key determinants of the spread of HIV in Ghana being functionally coordinated and effective. This is particularly so with regards to interventions and medical services to the vulnerable groups, increase condom use, reduction in stigmatization and discrimination, decrease in sex with multiple and concurrent partners, gender equity, social inequalities and inequities and economic empowerment of women.

The reality is that of those identified as living with the disease, a quarter was unaware of their infection and unable to benefit from clinical care and may transmit the disease unknowingly (Mathers et al., 2008; National AIDS Control Programme, 2013). As of 2003, there were an estimated 350,000 people living with HIV/AIDS in Ghana (Kates \& Jennifer, 2004; National AIDS Control Programme, 2013). The HIV/AIDS prevalence rate (the percent of people living with the disease) in Ghana is reported to be low compared to the sub-Saharan African region overall, and appears to be fairly stable. Despite, there are an increasing number of people living with HIV/AIDS in Ghana, which poses challenges to prevention and treatment efforts (NACP/GHS, 2013). The Government of Ghana created a National Advisory Commission on AIDS (NACA) in 1985 and established a National AIDS Control Program (NACP) in 1987. The Ghana AIDS Commission was inaugurated in 2000, followed by the implementation of the country's National Strategic Framework (NSF) on HIV/AIDS for 2001-2005 (Ghana AIDS Commission, 2005).

\subsection{Competing Best National and International Standards against HIV and AIDS}

Since the late 1980's, there have been concerns about the best approach to combat HIV/AIDS in both the western industrialized nations and the developing nations. The main question that has pre-occupied the minds of public health officials in these nations was how to frame national interventions and response to HIV/AIDS. Amongst the earliest push back on the intervention policies raised in the late 80's was whether HIV should be tackled with the "broad statutory provisions established to control the spread of sexually transmitted and other communicable diseases” such as tuberculosis (Burris, Finucane, Gallagher, \& Grace 1996; Burris, 1999). Alternatively stated, the issue was whether HIV/AIDS as a communicable disease should be approached from the human rights angle or was it a public health disease control issue?

The popular conclusion of the kind of approach to combat the disease was that, HIV/AIDS was like any other communicable disease and should be approached as such. Thus, the control program should be given full faith and credit to tried and tested measures such as mandatory testing, quarantine and isolation to combat it (Bayer, 1991).

\subsection{The "Exceptionalism" Debate on HIV and AIDS in the Western Industrialized Nations}

But even then, there were as many dissenting voices for the human rights approach as there were the many who advocated for a stricter epidemiological disease control, public health approach (Burris, 1999). Between the two seemingly dissimilar views, lay the real challenge that public health agencies had the authority but did not possess the power to compel the public. It was reasoned that such an approach was inspired by the germ theory of disease, where public health emphasized the elimination of the causal agent: the germ of HIV/AIDS. The argu- 
ment went on that it was best to look at HIV/AIDS not as a microbial health challenge but rather as both behavioral and environmental challenge in the design of interventions and mitigation. This would allow time to lead the way by way of strategy (Wolitski, Valdiserri, Denning, \& Levine, 2001).

The policy development in the western industrialized nations went full circle and came back to the starting point of the debate concerning the approach to combat the disease. The enduring resolution of the debate was that HIV/AIDS is a contagious disease that needs to be approached from the public health, epidemiological, disease control realm while being mindful of the human rights issues inherent in such an approach (Slack, 1998).

The analysis provided above is a very brief synopsis of the debate about how to approach HIV/AIDS interventions from either the public health, disease control point of view or from a human rights view point. These arguments made then in the western industrial world's attempts at minimizing the reach of the disease. It makes plenty of sense in the case of the emerging markets like Ghana in its current fight on HIV/AIDS.

Now, attention would be turned to the national paradigm on the disease. We would look at the prevention and management as well as the philosophical basis, if any, upon which the intervention measures against the disease have been driven. We would also assess the protective socio-legal ecosystem that may have been provided for those living with the disease to reduce stigma and discrimination as a by-product of risk communication and health promotion. But first, how does the national policy measure up if assessed against itself in terms of what the policy says on paper and what pertains on the ground. This inquiry is important because society's reaction to infectious diseases follows an ebb and flow pattern (Brachman, 2003).

\subsection{Juxtaposition of the National Policy vis-à-vis International Public Health Approach}

The Ghana HIV and AIDS, STI Policy, 2013 framework advocates for the simultaneous observance of the epidemiological, disease control impetus as well as the human rights focus. The duality of foci of the national policy framework appears to have contributed to internal confusion. The apparent confusion has undermined the thrust of the policy and the development of realistic implementation with the overall effect of creating a weak national policy, (NACP, 2013:19-21). Examining the approach adopted by other jurisdictions, it appears that adherence to disease control public health approach offers the best option to increasing treatment of people living with HIV, or maximizing the number of people who are aware of their status. A public health approach would also help to render routine testing with the ultimate goal of reducing the number of people who are unaware of their status and prevent new infections. Touting the positive outcomes of routine testing in 2006, it was found that the majority of persons who are aware of their status will reduce risk behaviors that could transmit disease by as much as 68\% per annum (CDC, 2007). Routine testing in Ghana is limited to segment of the population such as pregnant women who access ante-natal health services, but not as part of a national program targeting everybody and not just those accessing health care services (National Guidelines for Prevention of Mother to Child Transmission of HIV, 2014: 8-11).

\section{Method}

Our primary research goal was to identify the gaps in the national HIV/AIDS Policy in order to address them. We examined the Ghana HIV/AIDS and STI Policy (February, 2013) "as is" to look at the provision of judicial and legal mechanisms for testing, treatment and counseling as advocated by the policy. To accomplish this objective, we obtained from the Ghana AIDS Commission copies of their official working publications which are generally given away to the public as part of public education and engagement such as: The National Monitoring and Evaluation Plan for HIVIAIDS in Ghana 2006-2010; Ghana Country AIDS Progress Report (2012); UNAIDS Global AIDS Response Progress Report, 2010-2011; Ghana Public Health Act, 2012 (Act 851) and other grey material from the official website of the Ghana AIDS Commission. We also reviewed subsidiary publication by the GAC in furtherance of the policy. These documents were the National Guidelines for Prevention of Mother to Child Transmission of HIV, 2014 and HIV Sentinel Survey Report, 2014.

Finally, we looked at the existence of the national provisions against stigmatization and discrimination. The review was based on the Revised National HIV/AIDS and STI Policy of June 2012, which morphed into the National HIV/AIDS and STI policy of February 2013, other publications from the Ghana AIDS Commission as previously alluded to in this section. Documentary review of the existing national and international laws, policies and publications relevant to HIV/AIDS related issues was undertaken. This included publications from civil society, and civil society organizations as well as documentation on HIV/AIDS prepared and disseminated by 
supra-national institutions like the World Health Organization, UNAIDS, and other national institutions such as Centers for Disease Control of the United States of America and the Ghana Health Service.

Internet searches at sites such as Pub Med, Kaiser Family Foundation, Medline, Page Press, Sage and others were done, with phrases like "HIV/AIDS, the disease control public health approach", "partner notification and names reporting", "expedited partner treatment" and "stigmatization and discrimination of HIV challenged individuals" were employed in finding relevant literature.

We expanded the search to include the "physician-patient relationship", "issues of privacy", "informed consent" and "autonomy". Legal and other information culled from all the sources were organized into their various units and analyzed, based on the professional understanding of the authors of law, public health and medical ethics as well as human rights issues vis-à-vis epidemiologic disease control measures.

We assessed both the public health and human rights approach adopted by the National Policy to evaluate whether it was sound in preventing new infections, maximizing the treatment of people living with HIV and encouraging those who do not know their status to do so.

We also investigated the national policy on partner notification, names reporting in the context of power roles between the sexes, and expedited partner therapy in the case of MSM, and young people as additional control measure to ensure that the population took the issue of knowing their status seriously. In the case of expedited partner therapy, we investigated whether the regime should not be extended to couples in polygamous marriages where one partner may be HIV challenged. The data set collated was analyzed based on our skills and abilities in epidemiology, public health and human rights law as well as disease surveillance and intervention vis-à-vis international best practice.

\section{Results}

\subsection{Reliability of the Historical Prevalence of HIV/AIDS}

The national policy document provided that the last population based survey on HIV prevalence carried out in Ghana was through the Ghana Demographic Health Survey (GDHS) of 2003. Since then HIV prevalence has been estimated based on sentinel surveillance of pregnant women attending Ante Natal Clinics and through the Estimation and Projection Package modeling. It is doubtful if statistics about HIV prevalence of men who have sex with men (MSM) or those of Female Sex Workers (FSW) would show up with sentinel data on prevalence collected from Ante Natal Clinics of pregnant women. Although by proxy, an infected pregnant woman could be presumed to have also infected the man responsible for her pregnancy or the other way around, such a conclusion may not always fit the situation. Could the downward slide of HIV prevalence in Ghana be attributable to the absence of reliable figures on say, the total population of men who have sex with men, for example or that of female sex workers? Female sex workers are not a static group with fixed registration and identity/enrolment cards showing their professions. There are constant in-flows and out-flows of female sex workers into the normal stream of commerce. These movements depend on the fundamentals of the national economy, economic opportunities available to women in general and how these trickle down to those lowest on the totem pole.

Therefore, to assume that somehow their finite numbers have been captured in any sentinel survey is preposterous. Perhaps, a better system needs to be developed to capture all the players in a unit taking into consideration the variables unique to each sub-unit. Not all pregnant women visit Ante Natal Clinics and so even within that sub-unit, it is doubtful if all the participants have been captured. The Estimated Projection Package (EPP) in 2008 estimated the national HIV prevalence among adults to be $1.9 \%$ (range $1.7 \%-2.2 \%$ ) and urban and rural prevalence estimated at $2.3 \%(0.7 \%-5.8 \%)$. The national median HIV prevalence showing three peak levels, were (3.6\%) in 2003, (3.2\%) in 2006 and in 2008 it came to (2.9\%). Again, although in 2007 and 2008 there were increases in the prevalence of HIV, a linear trend analysis showed that the prevalence since 2003 was on the downward slide.

Even as the National Policy paper quoted these statistics to support the downward trend, it also reported that people who inject drugs (PWID), female sex workers (FSW) and men who have sex with men (MSM) and their clients and partners contribute a whopping $40.6 \%$ of new infections to the national statistics (Ghana Country AIDS Progress Report, GAC, 2012: 24). Is the $40.6 \%$ new infections included in the downward slide or is it truly a new high, given the 10-year lag time in HIV developing into AIDs? If it is a new high, what is the multiplier effect of the $40.6 \%$ increase on prevalence? What is the percentage of HIV infected persons in Ghana who are unaware of their status? The percentage of HIV infected persons unaware of their status in case coun- 
tries for the US is $18 \%$, Australia is $15 \%$, Canada is $26 \%$, France is $33 \%$, Netherlands $40 \%$, Sweden $15 \%$ and Switzerland 25\% with UK registering 24\% (Yazdanpanah et al., 2010).

\subsection{Employing Public Health Tools for Disease Control}

We found that the Ghana HIV/AIDS Policy is built on a foundation of public health safety and human rights. Human rights and public health are two independent axes in the health care delivery system but with competing rights and obligations, and with different beneficiaries. Whereas the key beneficiary of a human right policy is the individual or a group of individuals, the key public health beneficiary is the community at large. In situations where the community faces existential threat from a contagious disease or enemy combatant, these two concepts may not comfortably co-exist as a unified under-structure upon which an important national policy against the perceived threat is erected.

Public health, according to the US Institute of Medicine, IOM is what society collectively do to assure the people of conditions for health, while at the same time observing basic ethical standards. These standards include autonomy, informed consent, non-malfeasance, choice, due process, equal protection, justice and truthtelling. In public health emergency requiring, for example, quarantine and isolation in order for society to collectively prevent diseases, prolong life, and promote the health of the community, many of such rights are suspended for the sake of the collective (Atrash \& Carpentier, 2012).

Although the National policy of 2013 proffers that "a public health approach priorities minimizing harm and disease transmission and utilizes judicial and legal principles as mechanisms for referral to services rather than punishment”, it nonetheless has failed to articulate what the judicial and legal principles ought to be or should have been since 1986 when the first 42 cases of HIV/AIDS in Ghana were confirmed. The most recently revised HIV/AIDS policy of 2013 does not contain such a blue-print.

\subsection{Anticipated Judicial and Legal Principles in National HIV/AIDS Policy}

\subsubsection{Names Reporting}

Names reporting initially faced fierce resistance from MSM. The vitriolic accusations that characterized the early reporting requirement have, at least, in the western industrialized nations given way to pragmatic disease control approach. In the Ghana Aids Commission's Policy, we found that the section under Chapter three of the revised policy dealing with Human Rights, Legal and Ethical issues, is too unsystematic to be included in a health policy document. However, the section in the GAC policy of August 2004 permitted a limited but self-seeking names reporting or "sharing of information" about HIV challenged patients with other health professionals. That document made it permissible for "professional purposes and in strict confidence" to disclose the HIV status of another to colleagues if the one making the disclosure has reason to believe that the colleague is endangered. Although the National Guidelines for Prevention of Mother to Child Transmission of HIV of 2014 states on page 12 that "Couple and partner HIV testing and counseling including disclosure should be encouraged, supported and offered", it is still left to the couple if they want to be tested. While the emphasis is on prevention of mother-to-child transmission, this was a great opportunity to include names reporting and information sharing.

In other jurisdiction, names reporting and information sharing about HIV challenged persons is to be made more transparent and utilitarian. For example, France adopted names reporting in 2003, followed by the United States of America in 2008. Sweden was the first nation to make HIV/AIDS a notifiable disease in 1983. At the individual State level, at various websites including those of New York and Georgia, judicial and legal principles have been enacted by their State legislatures to aid the public health official in the conduct of HIV interventions when it comes to information sharing.

Incidentally, since 1987 when the first HIV/AIDS cases were confirmed in Ghana, the nation has not managed to pass the HIVIAIDS Control and Prevention Law as proposed, which may have addressed such ethical and technical issues. For instance, the State of Georgia's statutes consider HIV/AIDS as...disease of public health importance and require both health care providers and laboratories to report case of HIV and AIDS. Health care providers should complete a HIV/AIDS Case Report Form on any patient with an HIV or AIDS diagnosis. Laboratories must report any test indicative of HIV infection. This includes but is not limited to confirmed positive HIV antibody tests, all CD4 counts, all viral load tests (including undetectable), or any HIV diagnostic test...” (Georgia Department of Public Health, 2015). 


\subsubsection{Expedited Partner Treatment}

The reality is that people in Ghana like those in other parts of the world, are engaged in multiple and concurrent sexual partners. For this reason and for reasons of effective surveillance of STIs, expedited partner treatment may be an effective way to reduce new infections of STIs. For those engaged in polygamous marriages where the partners may not be exclusive to each other, expedited partner treatment could provide a much needed support for STI prevention. Expedited Partner Treatment (EPT) is an intervention program for STI, where a partner under treatment is involved in the delivery of prescription or medication to the partner without the clinical assessment of the partner. Although there are ethical and legal issues in such a program, a recent study in the United States of America indicated that 12 jurisdictions legally permitted EPT and another 13 States probably permitted EPT, while 28 jurisdictions potentially allowed EPT depending upon each case. Today, California, Maryland, Tennessee and Minnesota have enacted express laws permitting EPT (Hodge, Pulver, Hogben, Bhattacharya, \& Brown, 2008).

\subsubsection{Partner Notification}

In 2000, the State of New York in its bid to address deficiencies in AIDs surveillance, introduced the Reporting and Partner Notification Law. It subsequently conducted an impact assessment of the law on HIV testing, new cases and health seeking behaviors of MSM. The study reported that the initial fears about partner notification that if implemented would lead to a reduction of testing among the vulnerable groups was unfounded. "The study was based on analyses of HIV testing trends before and after HIV name-based reporting and partner notification, and on in-person interviews of 761 high-risk individuals in four cities-Albany, Buffalo, Rochester, and Syracuse- -between 2001 and 2004. The study found that high-risk individuals had limited awareness of the reporting and notification law, and few cited concern about named reporting as a reason for avoiding or delaying HIV testing. The law had no effect on testing levels, post-test counseling rates or individuals' willingness to allow use of their names where the identification is held confidential by the Department of Health" (Hodge, Pulver, Hogben, Bhattacharya, \& Brown, 2008; Burris, Finucane, Gallagher, \& Grace, 1996; Burris, 1999).

Consider the case of HIV challenged persons who are engaged in polygamy in Ghana, where their counterparts in the marriage may not know of the others' infectivity. In such a situation, the adoption of partner notification as an enhanced surveillance tool is consistent with best international practice when it comes to HIV/AIDS as a public health concern.

\subsubsection{Mandatory Testing vis-à-vis Universal Precautions}

The GAC policy gives confusing statements about testing and seems to be pandering to Human Rights advocates rather than to serious epidemiological disease surveillance, investigation and control. For example, Section 5.4 of the GAC policy of August 2004, which is incorporated into the Revised Policy of 2013, maintains that "mandatory HIV testing shall not be part of... pre-surgical procedures". In the same section of the document, at section 5, sub-section 5.2, the GAC advocates that "professional disclosure of the status of an HIV positive patient to an endangered third party shall be made as permitted by law". In order to make such a disclosure, does one need to know the details of what one is disclosing, which pre-supposes some form of primary and confirmatory test to reach such a conclusion?

The application of universal precautions also require health care institutions to take specific and appropriate measures to protect health care workers against the risk of infection and reduction of nosocomial transmission at each level. This also presumes some form of pre-treatment investigation, test and confirmation. So the idea that mandatory testing is not allowed by the GAC policy is ludicrous (National Guidelines on PMTCT 2014: 12-14). In addition to protecting health care workers by ensuring pre-surgery testing, mandatory testing is allowed for blood donated for transfusion or donors and recipients of body fluids and tissues. Mandatory testing also applies to individuals charged with rape and defilement. Diagnostic testing of patients on the basis of clinical symptoms and signs for diagnosis is also permissible.

Additionally, routine (mandatory) testing is required of pregnant women, key populations such as MSM, patients in hospital Emergency Rooms, In-patients, adolescents attending adolescent friendly services, STI services, patients with Tuberculosis, and those who have experienced potential occupational or sexual exposure. Yet, in the National Guidelines for PMTCT of 2014, it allows that, "Certain women will continue to decline testing and their decision shall be respected and documented in the medical record. Their refusal shall not compromise the quality of care they receive". 
Evidently, there is confusion of purpose and interpretation of the GAC policy when it comes to the issue of mandatory testing of potential HIV infected persons as a means of disease surveillance.

\subsubsection{Human Rights Issues and Ethics}

Both the August 2004 and the 2013 policies of the GAC devote a great deal of space and energies to human rights protections but not to medical ethics from investigative and epidemiologic points of view. This development gives the impression that the primary focus of the two documents is on human rights and but not on disease prevention and treatment. Under a strict human rights regime, there would have been no room for mandatory testing of any kind as articulated in the two documents. The GAC policy appears to confuse what happens to medical ethics such as physician-patient confidentiality, autonomy and informed consent in public health emergencies with human rights protections. The rule of thumb in public health emergencies is that certain civil rights may be suspended or weakened from strict constitutional and procedural protections to allow health professionals the opportunity to control the particular health risk to the rest of the population (Ghana Public Health Act, 2012; Jacobson v. Massachusetts, 1905).

By so doing, the Ghana Aids Commission (GAC) by default, perhaps, intentionally, has given the biggest support and endorsement to MSM in a nation whose public policy and criminal law legislation criminalizes men having sex with men. Although such a public support is not in and of itself wrong, it is misplaced in a disease control policy. What is uncanny about such a move by the GAC is that New York city which arguably has a bigger population of MSM in comparison to that of Ghana did in 2000 introduce legislation on partner names reporting and have EPT program for effective disease control and surveillance.

In fact, by ensuring that HIV challenged persons are identified and receive treatment not through coercive measures but third party assisted programs such as partner notification and also through voluntary participation, is the core duty of medical ethics in public health.

The basic tenets of medical ethics allows the public health official to weigh the interests of the patient against the interest of the community at large. Since all agree that HIV/AIDS is contagious disease posing grave threat to the health of the public, the issues of individual interests for privacy, for example, cannot override the needs of the community. Since people that are HIV challenged are also members of the community, when the community's interests are protected, it covers those who are HIV challenged as well. This makes it superfluous to carve out exceptions for those that are HIV challenged to the extent that their needs appear to be superior to those of the community at large.

\subsubsection{Stigmatization and Discrimination}

The two GAC policy documents of 2004 and 2013 have provided a litany of reasons against stigma and discrimination but failed to provide specific policy directions against stigma and discrimination. The section on Reduction of Stigma and Discrimination in the policy states that:

"The main object of mitigation is to reduce HIV and AIDS related stigma and discrimination towards persons infected or affected by HIV and AIDS and key and vulnerable populations and draw attention to the compelling public health rationale to overcome stigmatization and discrimination against them in society. This policy mitigates stigma and discrimination through information, collaborated multi-sectoral advocacy, policy and monitoring."

Incidentally, the above quoted paragraph does not tell what constitutes stigma and discrimination. The August 2004 does not fare any better. Section 4.1 actually deals with Non-discrimination in Research and does not address stigma and discrimination with any degree of specificity. Section 5.3 on Workplace HIV/AIDS, instead of setting the modalities for workplace compliance with equal protection and treatment of all workers irrespective of one's HIV status, delegates such assignment to the Ministry of Employment and Manpower Development. It also refers the reader to conventions developed by the International Labor Organization. Other nations such as Australia have enacted explicit legislation against discrimination on the grounds of HIV status (Bowtell, 2005; Hanson, 2011). The media has been used to provide extensive coverage of HIV related discrimination cases as anti-stigma measure. In other nations such as the Netherlands, employers have been asked to develop specific non-discriminatory modalities for the employment and retention of HIV challenged persons (Henriksson \& Ytterberg, 1992; Abelard \& Alexander, 2003; de Zwart, Sandfort, \& van Kerkhof, 1998). All though the 1992 constitution of Ghana has anti-discrimination provisions, given the nations attitude and official stance towards ho- 
mosexuality, it is not inconceivable for those provisions to be interpreted to exclude MSM who are HIV challenged on cultural imperialism grounds (Norman, Aikins, \& Binka 2012).

\section{Discussion}

The Ghana Aids Commission (GAC) in its revised policy document of 2013 stated amongst the challenges facing the Commission to include policy gaps in the private sector response, slow uptake of workplace HIV programs, weak capacity of civil society organizations and intra- and inter-governmental, ministerial coordination problems. Missing in this litany of challenges are: the lack of legislation on HIV and Aids in Ghana, the lack of anti-discrimination legislation specifically addressing stigma and discrimination, the lack of public health epidemiologic disease control focus of the national policy, the lack of partner notification legislation, the lack of expedited partner treatment, the lack of names reporting as an effective tool for disease surveillance and public health research. These are the props upon which a good national policy for a reduction in HIV transmission, treatment and prevention should be based.

\section{Conclusion}

The GAC set 2015 as the cut off point for achieving these targets: reducing new infections from 12,077 in 2011 to 9022; and reducing deaths from HIV/AIDS of 15,263 in 2011 to 6,350. The number of children in 2011 with HIV/AIDS was 1707, which is to fall to 824 in 2015. If these targets were to be met, these would be laudable achievements. Despite this, it is imperative for the GAC to adopt a specific legislation on names reporting, partner notification, stigma and discrimination. Although in Ghana today there appears to be wide spread accommodation, tolerance and acceptance of those living with HIV AIDs, there is no real surveillance to ascertain the true situation on the ground. There is no national legislation and enforcement mechanism specific to those living with HIV AIDs, although the national policy is largely driven from the Human Rights lens and less from the point of view of epidemiology and contagious disease public health intervention approach.

\section{References}

Abelard, P., \& Alexander, S. (2003). Anglo-American Ethics (20 ${ }^{\text {th }}$ Century). A History of Western Ethics, 173.

Atrash, K., \& Carpentier, R. (2012). The Evolving Role of Public Health in the Delivery of Health Care. Revista Brasileira de Crescimento E Desenvolvimento Humano, 22, 396-399.

Bayer, R. (1991). Public Health Policy and the AIDS Epidemic: An End to HIV Exceptionalism? New England Journal of Medicine, 324, 1500-1504. http://dx.doi.org/10.1056/NEJM199105233242111

Bowtell, W. (2005). Australia’s Response to HIV/AIDS 1982-2005. Lowy Institute for International Policy. http://m.lowyinstitute.org/files/pubfiles/Bowtell,_Australia's_Response_to_HIV_AIDS_logo.pdf

Brachman, P. S. (2003). Infectious Disease-Past, Present and Future. International Journal of Epidemiology, 32, $684-686$. http://dx.doi.org/10.1093/ije/dyg282

Burris, S. (1999). Studying the Legal Management of HIV-Related Stigma. American Behavioral Scientist, 42, $1229-1243$. http://dx.doi.org/10.1177/0002764299042007012

Burris, S., Finucane, D., Gallagher, H., \& Grace, J. (1996). The Legal Strategies Used in Operating Syringe Exchange Programs in the United States. American Journal of Public Health, 86, 1161-1166. http://dx.doi.org/10.2105/AJPH.86.8_Pt_1.1161

Centers for Disease Control and Prevention (CDC, P., \& Others) (2007). Rapid HIV Testing in Emergency Departments-Three US Sites, January 2005-March 2006. MMWR. Morbidity and Mortality Weekly Report, 56, 597.

de Zwart, O., Sandfort, T., \& van Kerkhof, M. (1998). No anal Sex Please: We're Dutch: A Dilemma in HIV Prevention Directed at Gay Men. The Dutch Response to HIV: Pragmatism and Consensus, 135-152.

Georgia Department of Public Health (2015). Georgia’s HIV/AIDS Epidemiology Surveillance Section. http://dph.georgia.gov/georgias-hivaids-epidemiology-surveillance-section

Ghana AIDS Commission (2005). The National Monitoring and Evaluation Plan for HIVIAIDS in Ghana 2006-2010. Ghana AIDS Commission.

Ghana Country AIDS Progress Report (2012). UNAIDS Global AIDS Response Progress Report, 2010-2011.

Ghana Public Health Act (2012). Ghana Public Health Act 851. Government Printer, Assembly Press, ACCRA. GPC/A753/ $350 / 11 / 2012$. 
Hanson, F. (2011). Australia and the World: The Lowy Institute Poll 2010. Sydney: Lowy Institute for International Policy.

Henriksson, B., \& Ytterberg, H. (1992). Sweden: The Power of the Moral(istic) Left. In D. L. Kirp, \& R. Bayer (Eds.), AIDS in the Industrialized Democracies-Passions, Politics and Policies (pp. 317-338). New Brunswick: Rutgers University Press.

Hodge Jr., J. G., Pulver, A., Hogben, M., Bhattacharya, D., \& Brown, E. F. (2008). Expedited Partner Therapy for Sexually Transmitted Diseases: Assessing the Legal Environment. American Journal of Public Health, 98, 238-243. http://dx.doi.org/10.2105/AJPH.2007.113381

Jacobson v. Massachusetts, 197 US 11 (1905).

Kates, J. (2004). Trends in US Government Funding for HIV/AIDS. http://www.terrymichael.net/hivsources/PDF\%20Note\%20Files/HIV-AIDS Notes Number28 AIDS US FundingTo 20 14.pdf

Mathers, B. M., Degenhardt, L., Phillips, B., Wiessing, L., Hickman, M., Strathdee, S. A. et al. (2008). Global Epidemiology of Injecting Drug Use and HIV among People Who Inject Drugs: A Systematic Review. The Lancet, 372, 1733-1745. http://dx.doi.org/10.1016/S0140-6736(08)61311-2

Ministry of Health (2014). National Guidelines on Prevention of Mother to Child Transmission of HIV. NACP, Accra, Ghana.

National AIDS Control Program/Ghana Health Service (NACP/GHS 2013). HIV Sentinel Survey Report 2013.

National AIDS Control Programme. (2013). National HIV and AIDS, STI Policy.

Norman, I. D., Aikins, M., \& Binka, F. N. (2012). The Legislative and Policy Gaps in the National HIV/AIDS and STI Policy, 2004-2012. White Paper, School of Public Health, University of Ghana, and the Office of the President, Ghana Government.

Slack, J. D. (1998). HIV/AIDS and the Public Workplace: Local Government Preparedness in the 1990s. Tuscaloosa, AL: University of Alabama Press.

Wolitski, R. J., Valdiserri, R. O., Denning, P. H., \& Levine, W. C. (2001). Are We Headed for a Resurgence of the HIV Epidemic among Men Who Have Sex with Men? American Journal of Public Health, 91, 883-888. http://dx.doi.org/10.2105/AJPH.91.6.883

Yazdanpanah, Y., Sloan, C. E., Charlois-Ou, C., Le Vu, S., Semaille, C., Costagliola, D. et al. (2010). Routine HIV Screening in France: Clinical Impact and Cost-Effectiveness. PLOS ONE, 5, e13132. http://dx.doi.org/10.1371/journal.pone.0013132 